\title{
Comparison of different intraocular pressure measurement techniques in normal eyes and post small incision lenticule extraction
}

This article was published in the following Dove Press journal:

Clinical Ophthalmology

14 July 2017

Number of times this article has been viewed

\author{
Mohamed Hosny \\ Fayrouz Aboalazayem \\ Hoda El Shiwy \\ Mohsen Salem \\ Department of Ophthalmology, \\ Cairo University, Giza, Egypt
}

Correspondence: Mohamed Hosny Department of Ophthalmology, Cairo University, 84 Shehab Street, Mohandeseen, Giza, I24I I, Egypt Tel +20 l 000007675

Emailmohamedhosny@mac.com

\begin{abstract}
Purpose: The purpose of the study was to determine the accuracy of intraocular pressure (IOP) measurement after small incision lenticule extraction (SMILE) using Goldmann applanation tonometry (GAT) and ocular response analyzer (ORA).

Methods: This is a prospective clinical study that was conducted on 30 eyes in the interval between February 2016 and September 2016. The age of the patients ranged between 19 and 40 years. The patients underwent SMILE surgery using the femto laser. IOP was measured preoperatively and 1 month postoperatively by both techniques, the GAT and the ORA.

Results: GAT recorded lower values than ORA values (IOPcc) preoperatively and postoperatively and the difference was statistically significant. Both GAT and ORA IOP measurements decreased after SMILE. There was no statistically significant correlation between the changes in the GAT and ORA readings and the postoperative corneal pachymetry or the lenticule thickness. Both corneal hysteresis and corneal resistance factor showed significant decline after the procedure, which correlated with the lenticule thickness.
\end{abstract}

Conclusion: SMILE causes significant reduction in IOP measurement by ORA and GAT. Corneal biomechanics decreases following SMILE and this correlates with lenticule thickness.

Keywords: ocular response analyzer, small incision lenticule extraction, corneal hysteresis

\section{Introduction}

Intraocular pressure (IOP) is an important routine for ophthalmological examination. It is an important risk factor for glaucoma. ${ }^{1}$ Adequate measurement of IOP is crucial for early diagnosis and management of glaucoma.

Nowadays, refractive surgery became very popular, which affects the central corneal thickness and corneal biomechanics which in turn affect IOP readings measured by using the traditional methods.

Several studies were conducted to assess the ease and accuracy of IOP measurement following refractive surgery especially LASIK. The aim of the current study was to assess the ease and accuracy of IOP measurements before and after small incision lenticule extraction (SMILE) using the Goldmann applanation tonometry (GAT) and the ocular response analyzer (ORA) and the effect of the surgery on corneal biomechanics.

\section{Materials and methods}

\section{Study design}

This study is a prospective clinical study that was conducted on 30 eyes in the interval between February 2016 and September 2016. Approval was obtained from the Cairo University Hospitals ethical committee to ensure the adherence of the study to 
the rules of the Helsinki declaration. Patients were divided into 2 groups: Group $A$ including 30 corneas of patients before undergoing femto SMILE surgery and Group $B$ including 30 corneas of the same patients 1 month after femto SMILE surgery.

The study included patients who were candidates for SMILE, aged $>18$ years, both the sexes are enrolled, with myopic refractive error or myopic astigmatism and with clear corneas. The exclusion criteria included patients with corneal pathology such as scarring and keratoconus and patients with history of previous ocular surgery.

\section{Preoperative assessment}

A complete ocular and medical history was obtained, with particular attention paid to the presence of collagen vascular disease, hormonal changes such as pregnancy, previous refractive or other anterior segment surgery, ocular injuries, and vitreoretinal surgery or disease. Medications and allergies were also noted. Written informed consent was obtained after detailed instruction and discussion. Soft contact lens wearers were required to leave their lenses out for 1 week.

All patients underwent the following tests before surgery: slit lamp exam, measurement of best corrected visual acuity (BCVA), manifest refraction, assessment of cornea using Pentacam (Pentacam ${ }^{\circledR}$, Oculus, Wetzlar, Germany) and ocular response analyzer (ORA) (model 30 classic, software version 2.0; Reichert, New York, NY, USA), measurement of central corneal thickness (CCT, Pachymetry) by Pentacam (Pentacam ${ }^{\circledR}$, Oculus), measurement of IOP using applanation tonometry (Goldmann tonometer; Haag-Streit, Koeniz, Switzerland), and ORA (Reichert Ophthalmic Instrument, Inc., Buffalo, NY, USA).

\section{Surgical technique}

The surgery was performed bilaterally and under topical anesthesia using three drops of Topical Benoxinate (Benoxinate hydrochloride $0.4 \%$ ) 2-3 min before surgery.

A VisuMax 500-kHz femtosecond laser (Carl Zeiss Meditec AG, Jena, Germany) was used for SMILE treatment. First, the back of the intrastromal lenticule was created by photodisruption from the periphery to the center, followed by the creation of the lenticule front from the center to the periphery and an incision tunnel located at 11 o'clock. The lenticule diameter was $6.5 \mathrm{~mm}$ and the cap diameter was $7.5 \mathrm{~mm}$. The incision length was $2.0-2.5 \mathrm{~mm}$. The intended cap thickness was 100-110 $\mu \mathrm{m}$. After laser treatment, a thin blunt spatula was inserted through the incision site to break the remaining tissue bridges and loosen the stromal lenticule, which was pulled out using McPherson forceps and removed. After the removal of the lenticule, the stromal pocket was flushed with saline.

\section{Postoperative assessment}

In addition to routine assessment, pachymetry and IOP were re-evaluated 1 month after performing the refractive surgery using the same devices. Although the full preoperative assessment was performed by a single assistant, the postoperative assessment was carried out by a different person to ensure that the study is properly blinded.

\section{Statistical analysis}

Data were coded and entered using the statistical package SPSS version 23 and were summarized using mean and standard deviation or median and interquartile range according to their distribution whether normal or nonparametric. Shapiro Wilk was used for testing normality of distribution in each parameter. Comparisons between paired measurements in each patient were done using paired $t$-test or the nonparametric Wilcoxon signed rank test. Comparisons between unpaired measurements in each patient were done using unpaired $t$-test or the nonparametric Mann-Whitney $U$ test. Correlations between quantitative variables were done using Pearson correlation coefficient or Spearman correlation coefficient. $P$-values $<0.05$ were considered as statistically significant. No statistical correction was performed for including both the eyes of same patients.

\section{Results}

This study included 30 eyes of 15 patients with age ranging from 19 to 40 years who underwent femto SMILE procedure, and $53.3 \%$ of them were male.

Patients' demographics, preoperative and postoperative pachymetry, and IOP values are summarized in Table 1 . The preoperative IOP measured by ORA was significantly higher than that measured by GAT $(P=0.007)$ and the comparison was done using the nonparametric Mann-Whitney $U$ test (Figure 1).

Spearman correlation coefficient shows significant positive correlation between the preoperative GAT and the preoperative CCT $(P=0.011)$. However, no significant correlation was found between the preoperative IOP measured by ORA and CCT (Figure 2). The postoperative IOP was found to be significantly lower than the preoperative values when measured by both GAT and the ORA (IOPcc). The change between the preoperative and postoperative readings 
Table I Demographics and pre- and postoperative IOP values

\begin{tabular}{|c|c|c|c|}
\hline & Mean & $\begin{array}{l}\text { Standard } \\
\text { deviation }\end{array}$ & Median \\
\hline Age, year & 29.27 & 5.76 & 29.00 (19 to 40$)$ \\
\hline Refraction pre & -4.05 & 1.76 & $-4.00(-1.5$ to -8.5$)$ \\
\hline GAT pre, $\mathrm{mmHg}$ & 13.77 & 3.35 & $13.00(9$ to 20$)$ \\
\hline IOPcc pre, $\mathrm{mmHg}$ & 16.09 & 2.82 & $16.15(9.10$ to 21.9$)$ \\
\hline $\mathrm{CH}$ pre & 8.94 & 1.84 & $9.10(6.10$ to 13.20$)$ \\
\hline CRF pre & 8.63 & 2.16 & 8.75 (4.7 to 12.30) \\
\hline CCT pre & 515.93 & 32.73 & 505.00 (490 to 578$)$ \\
\hline Flap size, micron & 104.33 & 5.04 & $100.00(100$ to 110$)$ \\
\hline Lenticule thickness, micron & 88.97 & 19.41 & $86.00(6 \mid$ to $\mid 42)$ \\
\hline Refraction post & -0.34 & 0.50 & $-0.25(+0.5$ to -1.75$)$ \\
\hline GAT post, mmHg & 8.47 & 2.60 & 8.50 (4.0 to I5.0) \\
\hline IOPcc post, mmHg & 13.15 & 2.48 & 13.40 (7.9 to 18.1) \\
\hline $\mathrm{CH}$ post & 7.32 & 1.14 & 7.20 (4.9 to 10.0$)$ \\
\hline CRF post & 6.01 & $\mathrm{I} .47$ & $5.70(4.1$ to 9.8$)$ \\
\hline CCT post & 422.17 & 41.84 & 418.00 (4I0 to 498$)$ \\
\hline$\Delta \mathrm{GAT}, \mathrm{mmHg}$ & -5.30 & 2.67 & $-5.50(-10.0$ to -1.0$)$ \\
\hline$\Delta \mathrm{IOPcc}$ & -2.93 & 2.97 & $-2.35(-8.5$ to 1.9$)$ \\
\hline$\Delta \mathrm{CH}$ & -1.61 & 1.87 & $-1.60(-5.9$ to -1.3$)$ \\
\hline$\Delta \mathrm{CRF}$ & -2.62 & 1.49 & $-2.60(-5.30$ to 0.6$)$ \\
\hline
\end{tabular}

Abbreviations: GAT, Goldmann applanation tonometry; IOPcc, corneal compensated intraocular pressure measured by ORA; $\mathrm{CH}$, corneal hysteresis; $\mathrm{CRF}$, corneal resistance factor; CCT, central corneal thickness; pre, preoperative; post, postoperative.

(Delta change or $\Delta$ change) was higher in the GAT readings than the ORA readings (Figures 3 and 4).

Comparison was done using paired $t$-test showing statistically significant difference between the postoperative IOP readings by both GAT and ORA $(P<0.001)$ with lower IOP readings by GAT (Figure 5). Using Spearman correlation coefficient, no significant correlation was found between the degree of decline of the postoperative IOP readings by both

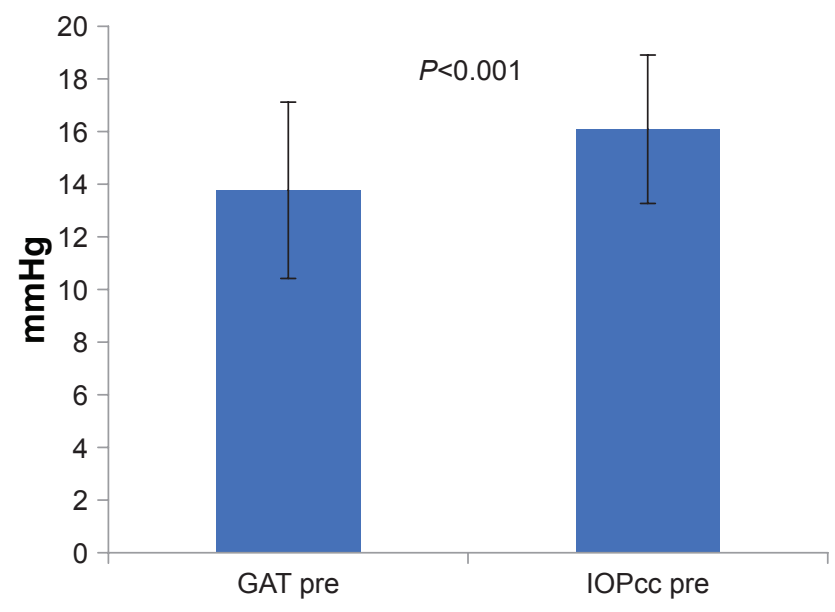

Figure I Comparison between GAT pre and IOPcc pre.

Abbreviations: GAT, Goldmann applanation tonometry; IOPcc, corneal compensated intraocular pressure measured by ORA; ORA, ocular response analyzer; pre, preoperative.

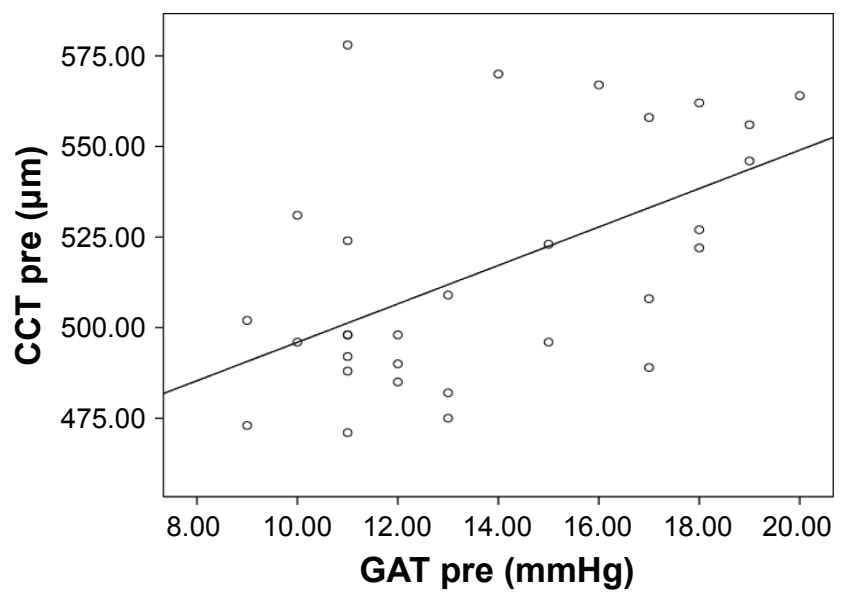

Figure 2 Correlation between the preoperative IOP measurement by GAT and preoperative CCT.

Abbreviations: IOP, intraocular pressure; GAT, Goldmann applanation tonometry; $\mathrm{CCT}$, central corneal thickness; pre, preoperative.

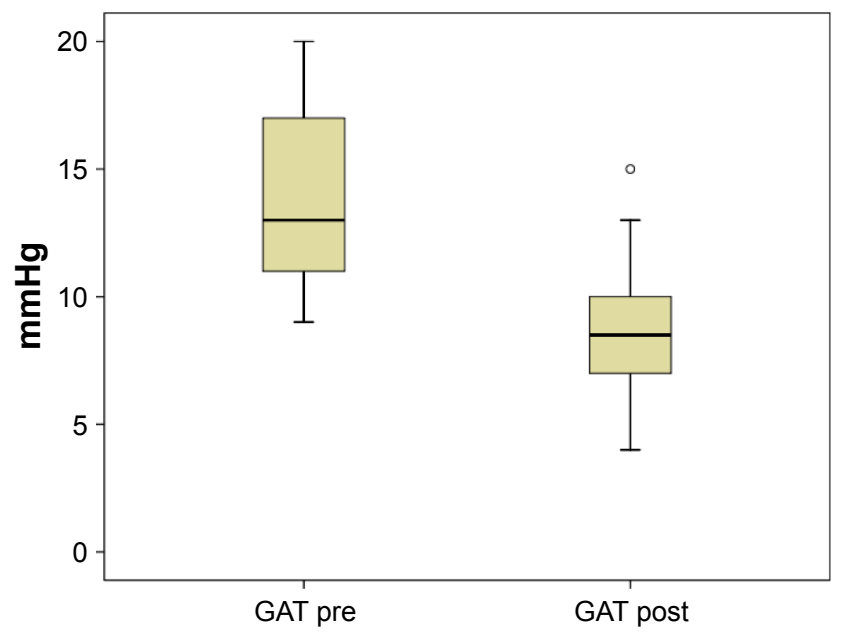

Figure 3 Comparison between preoperative and postoperative GAT measurements.

Abbreviations: GAT, Goldmann applanation tonometry; pre, preoperative; post, postoperative.

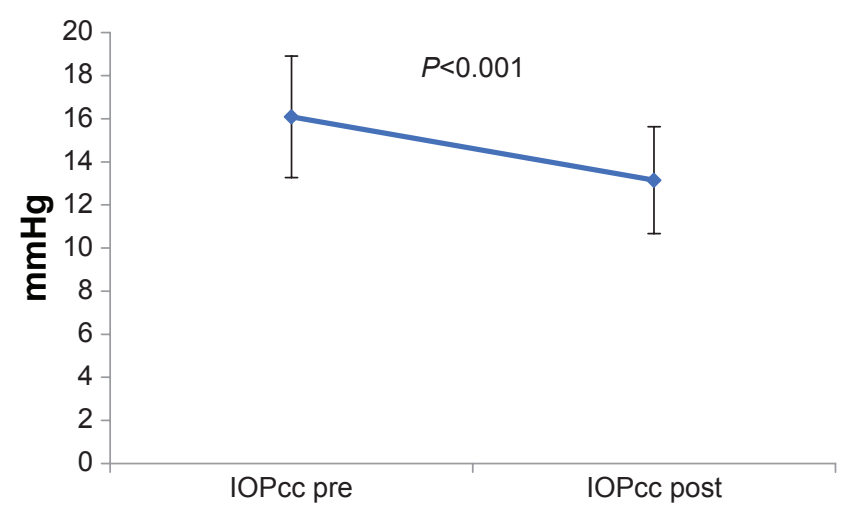

Figure 4 Comparison between pre and postoperative ORA measurements. Abbreviations: ORA, ocular response analyzer; IOPcc, corneal compensated intraocular pressure measured by ORA; pre, preoperative; post, postoperative. 


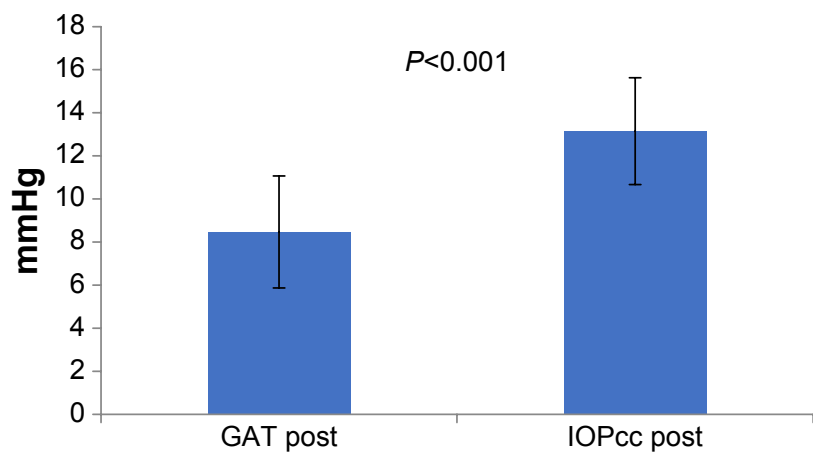

Figure 5 Graph showing comparison between postoperative intraocular measurement by GAT and ORA.

Abbreviations: GAT, Goldmann applanation tonometry; ORA, ocular response analyzer; IOPcc, corneal compensated intraocular pressure measured by ORA; post, postoperative.

methods and the postoperative pachymetry and the lenticule thickness or the postoperative CCT (Figures 6-9).

It was found that both corneal hysteresis $(\mathrm{CH})$ and corneal resistance factor (CRF) show significant decline after the procedure, and this decline was directly proportionate to the lenticule thickness (Figures 10-13).

\section{Discussion}

Corneal refractive surgery, such as femtosecond laserassisted laser in situ keratomileusis (FS-LASIK) and small incision lenticule extraction (SMILE), has emerged as having good efficacy, predictability, safety, and stability for surgical correction of low, moderate, and high myopia. ${ }^{2-4}$

However, CCT, corneal curvature, and corneal biomechanics change after corneal refractive surgery, which may affect IOP measurements. ${ }^{5}$ This prospective clinical study demonstrated that refractive surgery causes significant

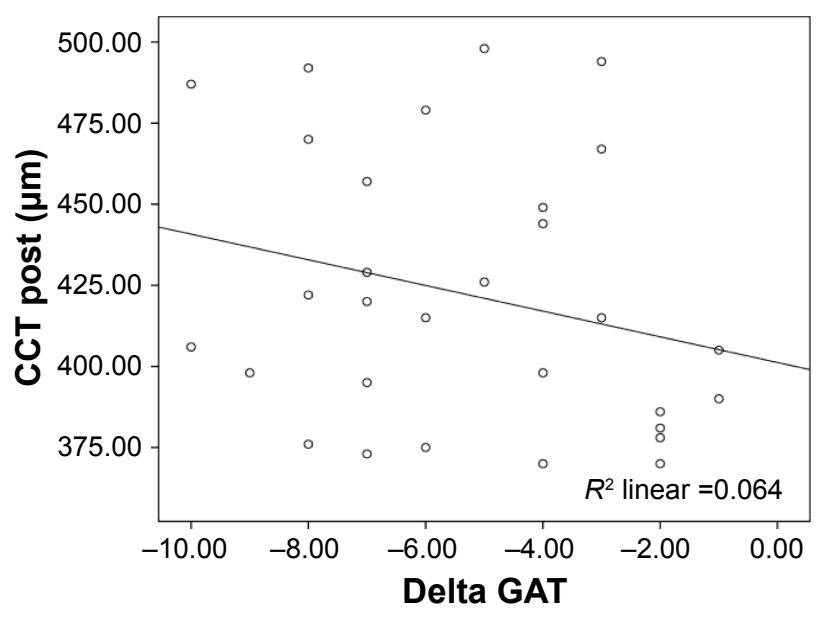

Figure 6 Correlation between CCT post and $\triangle \mathrm{GAT}$.

Abbreviations: CCT, central corneal thickness; GAT, Goldmann applanation tonometry; post, postoperative.

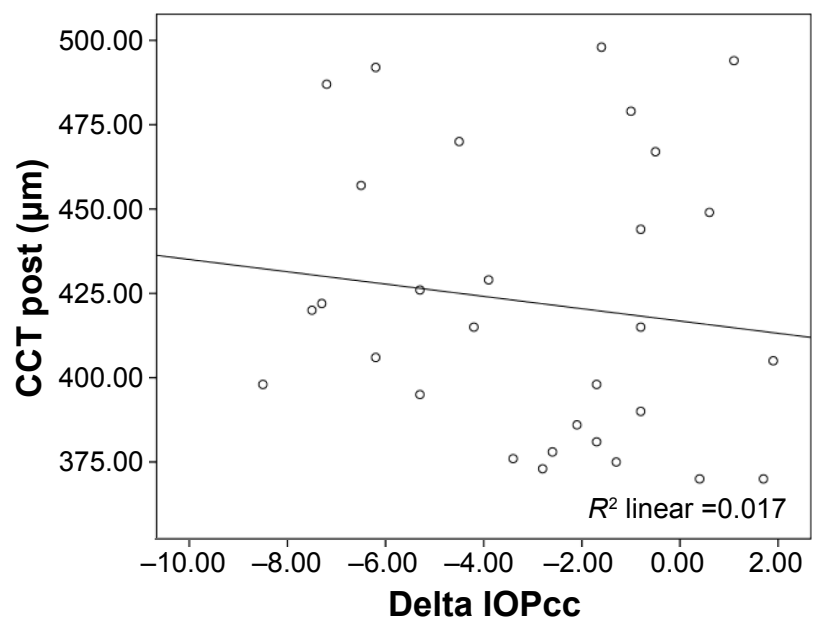

Figure 7 Correlation between CCT post and $\triangle \mathrm{IOPcc}$.

Abbreviations: CCT, central corneal thickness; IOPcc, corneal compensated intraocular pressure measured by ORA; ORA, ocular response analyzer; post, postoperative.

lowering of IOP measured using Goldmann applanation tonometry (GAT) and ORA.

Significant positive linear correlation was found between the preoperative measurement of the IOP by GAT and ORA ( $P=0.007, r=0.71)$ with ORA readings usually higher than GAT readings. In addition, significant positive linear correlation was found between the preoperative GAT and $\operatorname{CCT}(P=0.011, r=0.457)$. However, no significant correlation was found between the preoperative ORA measurement and CCT.

The results of previous studies are consistent with the finding of the present study which shows a strong correlation between GAT and CCT. ${ }^{6-8}$ However, Vandewalle et al

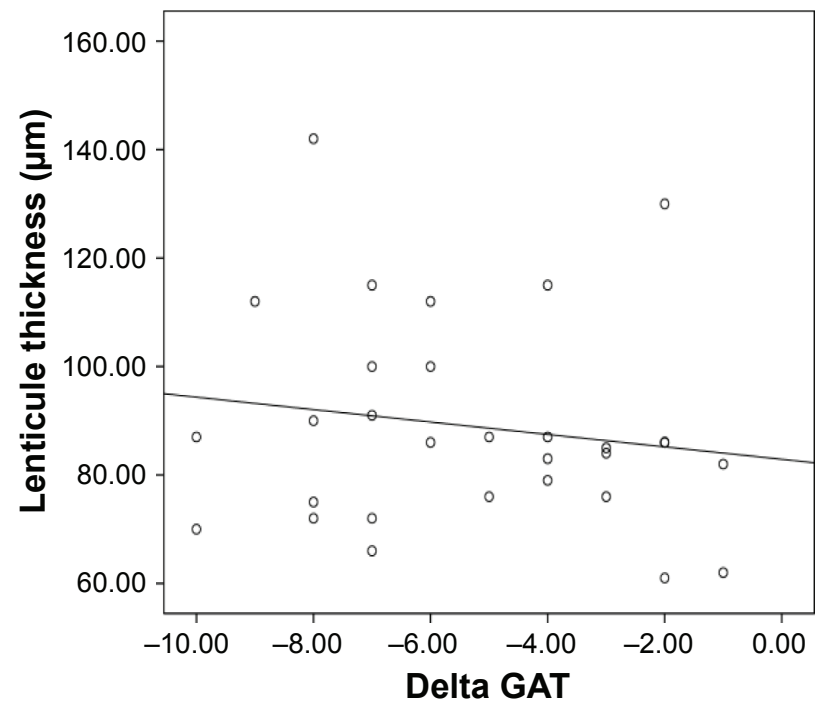

Figure 8 Correlation between the lenticule thickness and $\Delta \mathrm{GAT}$. Abbreviation: GAT, Goldmann applanation tonometry. 


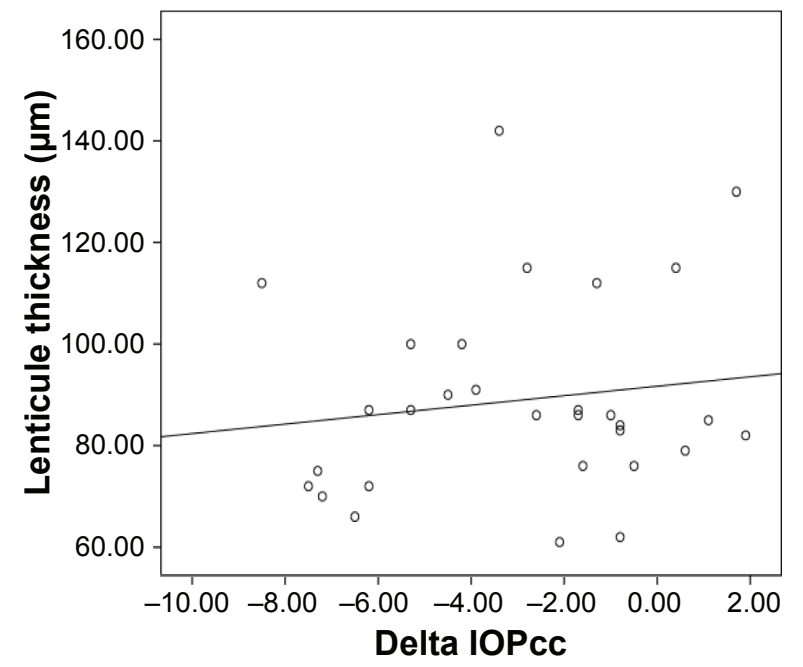

Figure 9 Correlation between the lenticule thickness and $\Delta \mathrm{lOPcc}$.

Abbreviations: IOPcc, corneal compensated intraocular pressure measured by ORA; ORA, ocular response analyzer.

found that IOP readings from Icare are in accordance with those from GAT, whereas CCT readings correspond well to (Goldmann correlated) ORA measurements and that there was no correlation between the IOP measurements and CCT for the four instruments. ${ }^{9}$

This study also found statistically significant decline in the postoperative (IOP) measurements by both GAT and ORA $(P<0.001)$. The decline in IOP was more in GAT when compared with ORA. The change in the GAT was $(-5.30 \pm 2.67 \mathrm{mmHg})$ whereas the change in the ORA was $(-2.93 \pm 2.97 \mathrm{mmHg})$.

Also, there is statistically significant decline in both $\mathrm{CH}$ and $\mathrm{CRF}$ (with $P=0.001)$. The change in $\mathrm{CH}$ was $(-1.6 \pm 1.87 \mathrm{mmHg}$ ) and the change in the CRF was $(-2.62 \pm 1.49 \mathrm{mmHg})$.

These results coincide with Dou et al who found that IOPg as measured by the ORA, IOPcc, CH, and CRF decreased greatly in both SMILE and LASEK groups after surgery $(P<0.05)$. However, an increase was observed in $\mathrm{CH}$ values 3 months after surgery. ${ }^{10}$

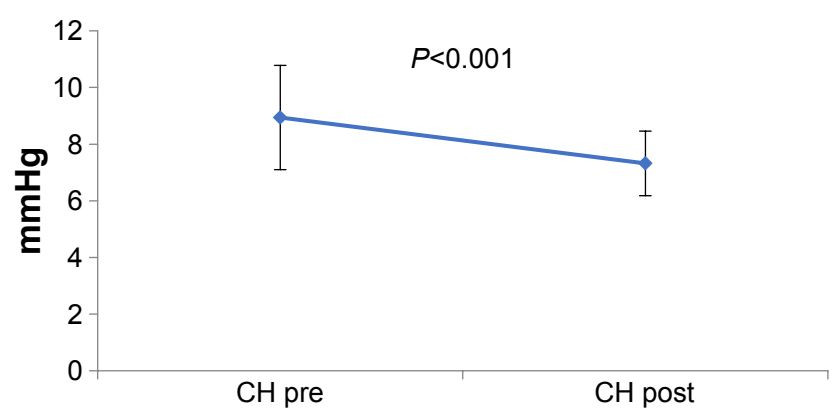

Figure 10 Comparison between pre and postoperative corneal hysteresis. Abbreviations: $\mathrm{CH}$, corneal hysteresis; pre, preoperative; post, postoperative.

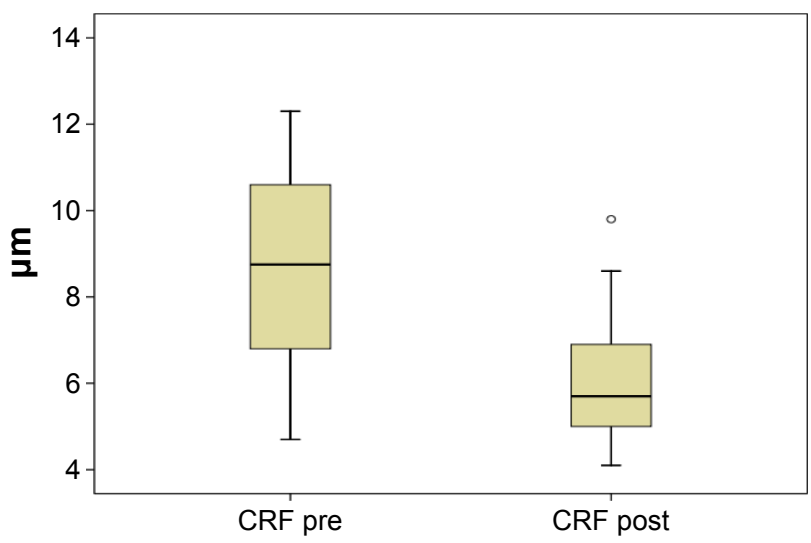

Figure I I Comparison between the pre and postoperative CRF.

Abbreviations: CRF, corneal resistance factor; pre, preoperative; post, postoperative.

Pedersen et al who evaluated corneal biomechanical properties after LASIK, ReLEx flex, and ReLEx SMILE by Scheimpflug-based dynamic tonometry (Corvis ST, Wetzlar, Germany) and ORA found that $\mathrm{CH}$ and $\mathrm{CRF}$ were significantly lower after all keratorefractive procedures compared to healthy controls $(P<0.05){ }^{11}$

This study found no significant relation between $\Delta \mathrm{GAT}$, $\Delta \mathrm{IOPcc}$, and the lenticule thickness $(P>0.05)$. This implies that the decrease in IOP readings cannot be predicted when the lenticule thickness is known, which is dependent on the refraction.

Significant correlation was found between $\triangle \mathrm{CH}, \triangle \mathrm{CRF}$, and the lenticule thickness $(r=-0.376, P=0.04$ and $r=-0.41$, $P=0.025$, respectively). The $\Delta \mathrm{CH} / \mathrm{LT}$ in this study was $(-0.018 \pm 0.01)$ and the $\Delta \mathrm{CRF} / \mathrm{LT}$ was $(-0.029 \pm 0.01)$.

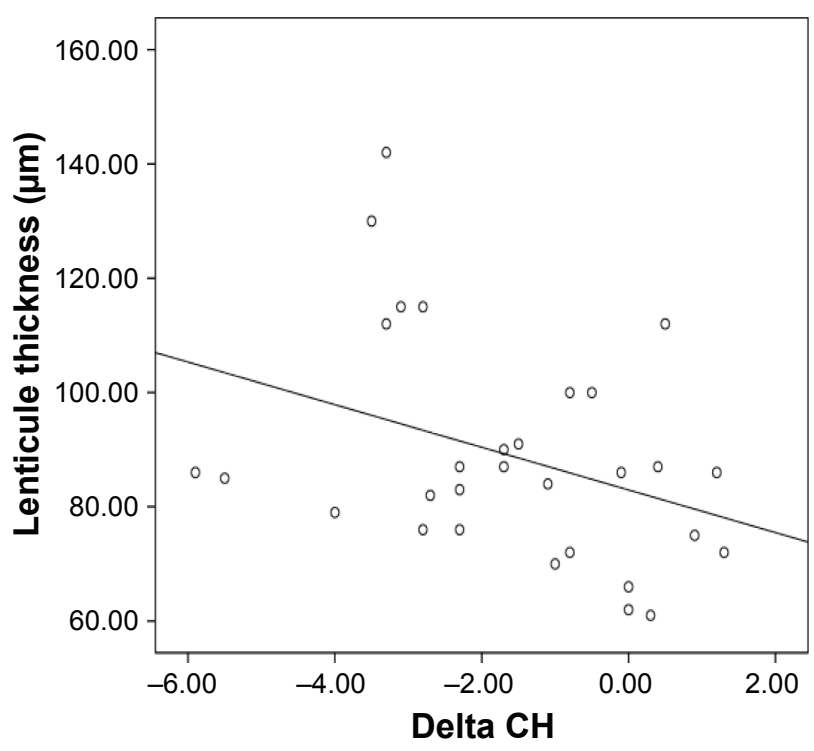

Figure 12 Correlation between the change in the corneal hysteresis $(\mathrm{CH})$ and the lenticule size. 


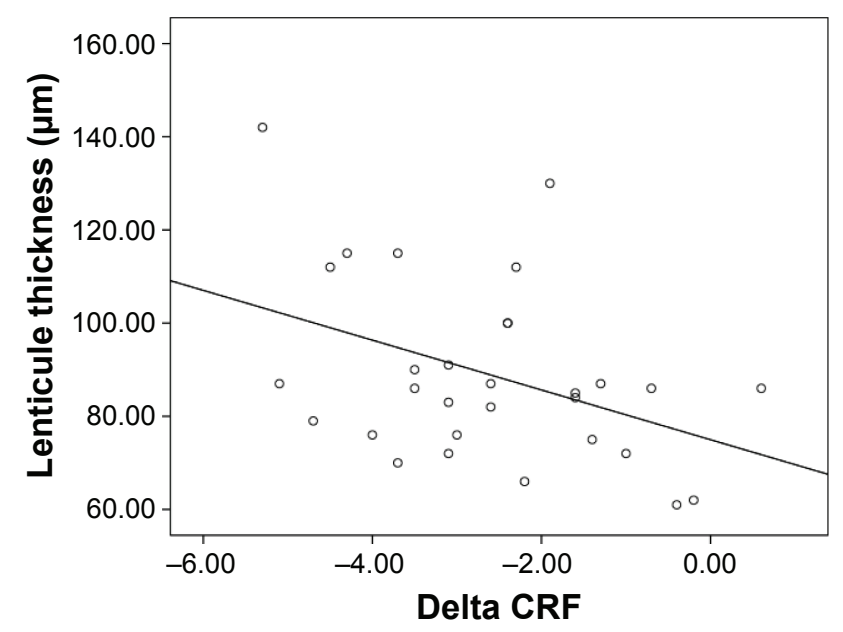

Figure 13 Correlation between the change in the corneal resistance factor (CRF) and the lenticule size.

Duo et al found that $\Delta \mathrm{CRF} / \mathrm{LT}$ and $\Delta \mathrm{CH} / \mathrm{LT}$ after SMILE were lower than the $\triangle \mathrm{CRF} / \mathrm{AD}$ and $\triangle \mathrm{CH} / \mathrm{AD}$ in the LASEK group, which meant that per unit of tissue removal, the decreases in CRF and $\mathrm{CH}$ are smaller in the SMILE group than in the LASEK group. This may be due to that after SMILE, most of the collagen fiber connections from the epithelium to the superior location of ablation, the Bowman layer, and the stiffer anterior stroma were preserved. ${ }^{10}$

Li et al found that $\triangle \mathrm{IOPg} / \mathrm{AD}$ and $\Delta \mathrm{IOPcc} / \mathrm{AD}$ in FS-LASIK were higher than $\Delta \mathrm{IOPg} / \mathrm{LT}$ and $\Delta \mathrm{IOPcc} / \mathrm{LT}$ in SMILE at the 6-month follow-up and $\triangle \mathrm{CRF}$ and $\triangle \mathrm{CH}$ per removed or ablated tissue in FS-LASIK were higher than in SMILE. ${ }^{12} \mathrm{Wu}$ et al found a noticeable decrease in the biomechanical parameters after both SMILE and FS-LASIK. After SMILE, corneal biomechanical parameter values were stable with no progressive deterioration during the 6-month follow-up. There was a positive recovery in $\mathrm{CH}$ 3 months and 6 months after surgery. The same recovery was not observed after FS-LASIK during the postoperative follow-up. ${ }^{13}$

\section{Disclosure}

The authors report no conflicts of interest in this work.

\section{References}

1. Kass MA, Heuer DK, Higginbotham EJ, et al. The Ocular Hypertension Treatment Study: a randomized trial determines that topical ocular hypotensive medication delays or prevents the onset of primary openangle glaucoma. Arch Ophthalmol. 2002;120:701-713.

2. Lee JK, Chuck RS, Park CY. Femtosecond laser refractive surgery: small-incision lenticule extraction vs. femtosecond laser-assisted LASIK. Curr Opin Ophthalmol. 2015;26(4):260-264.

3. Vestergaard A, Ivarsen AR, Asp S, et al. Small-incision lenticule extraction for moderate to high myopia: predictability, safety, and patient satisfaction. J Cataract Refract Surg. 2012;38(11):2003-2010.

4. Reinstein DZ, Carp GI, Archer TJ, Gobbe M. Outcomes of small incision lenticule extraction (SMILE) in low myopia. J Refract Surg. 2014;30(12):812-818.

5. Cheng AC, Fan D, Tang E, Lam DS. Effect of corneal curvature and corneal thickness on the assessment of intraocular pressure using noncontact tonometry in patients after myopic LASIK surgery. Cornea. 2006;25(1):26-28.

6. Carbonaro F, Andrew T, Mackey DA, Spector TD, Hammond CJ. Comparison of three methods of intraocular pressure measurement and their relation to central corneal thickness. Eye. 2010;24(7): $1165-1170$.

7. Oncel B, Dinc UA, Orge F, Yalvac BI. Comparison of IOP measurement by ocular response analyzer, dynamic contour, Goldmann applanation, and noncontact tonometry. Eur J Ophthalmol. 2009;19(6):936.

8. Shousha SMA, Abo Steit MA, Hosny MH, Ewais WA, Shalaby AM. Comparison of different intraocular pressure measurement techniques in normal eyes, post surface and post lamellar refractive surgery. Clin Ophthalmol. 2013;7:71-79

9. Vandewalle E, Vandenbroeck S, Stalmans I, Zeyen T. Comparison of ICare, dynamic contour tonometer, and ocular response analyzer with Goldmann applanation tonometer in patients with glaucoma. Eur $J$ Ophthalmol. 2009;19:783-789.

10. Dou R, Wang Y, Xu L, et al. Comparison of corneal biomechanical characteristics after surface ablation refractive surgery and novel lamellar refractive surgery. Cornea. 2015;34(11):1441-1446.

11. Pedersen IB, Bak-Nielsen S, Vestergaard AH, Ivarsen A, Hjortdal J. Corneal biomechanical properties after LASIK, ReLEx flex, and ReLEx smile by Scheimpflug-based dynamic tonometry. Graefes Arch Clin Exp Ophthalmol. 2014;252(8):1329-1335.

12. Li H, Wang Y, Dou R, et al. Intraocular pressure changes and relationship with corneal biomechanics after SMILE and FS-LASIK. Invest Ophthalmol Vis Sci. 2016;57(10): 4180-4186.

13. Wu D, Wang Y, Zhang L, et al. Corneal biomechanical effects: smallincision lenticule extraction versus femtosecond laser-assisted laser in situ keratomileusis. J Cataract Refract Surg. 2014;40(6):954-962.
Clinical Ophthalmology

\section{Publish your work in this journal}

Clinical Ophthalmology is an international, peer-reviewed journal covering all subspecialties within ophthalmology. Key topics include: Optometry; Visual science; Pharmacology and drug therapy in eye diseases; Basic Sciences; Primary and Secondary eye care; Patient Safety and Quality of Care Improvements. This journal is indexed on Submit your manuscript here: http://www.dovepress.com/clinical-ophthalmology-journal

\section{Dovepress}

PubMed Central and CAS, and is the official journal of The Society of Clinical Ophthalmology (SCO). The manuscript management system is completely online and includes a very quick and fair peer-review system, which is all easy to use. Visit http://www.dovepress.com/ testimonials.php to read real quotes from published authors. 